\title{
APAKAH SIKAP ALLAH DI PERJANJIAN LAMA BERBEDA DENGAN DI PERJANJIAN BARU?
}

\author{
Ali Salim
}

\begin{abstract}
Abstrak: Pendapat bahwa karakter Allah Perjanjian Lama yang kejam dan Allah Perjanjian Baru yang penuh kasih masih terus hidup hingga saat ini. Bagaimana respon gereja terhadap masalah ini dan bagaimana membuktikan bahwa Allah yang dikisahkan dalam Perjanjian Lama tidaklah sekejam seperti yang dibayangkan orang. Ia tetap Allah yang penuh kasih seperti Allah dalam Perjanjian Baru.
\end{abstract}

Kata-kata Kunci: Allah Perjanjian Lama berbeda dengan Allah Perjanjian Baru, Allah Perjanjian Lamakejam, Kematian Uza, Perang Suci, Hukuman Tuhan di Padang Gurun

Abstract: Some people still believe that character of God in the Old Testament is different from God in the New Testament. God in the Old Testament is cruel and God in the New Testament is love. How church response to this topic and how to prove that God in the Old Testament is not so cruel as some people think. He is a loving God as in the New Testament.

Keywords: The difference between Old Testament God and New Testament God, The Cruelty of Old Testament God, The Death of Uzzah, Holy War, God's Punishment to Israel in the desert

\section{PENDAHULUAN}

Ketika membaca Perjanjian Lama, banyak orang mendapat kesan bahwa Tuhan di Perjanjian Lama adalah Tuhan yang kejam dan penuh amarah. Ia tidak segan menghukum manusia dengan berbagai musibah dan malapetaka. Sebaliknya ketika membaca Perjanjian Baru, orang mendapat kesan bahwa Tuhan di Perjanjian Baru adalah Tuhan yang 
penuh kasih dan berbelas kasih terhadap orang berdosa. Tuhan di Perjanjian Lama terkesan pemarah sedangkan di Perjanjian baru terkesan sabar.

Problem ini sudah muncul sejak abad pertama. Di awal mula kekristenan, Marcion mengatakan bahwa Allah di Perjanjian Lama tidak sama dengan Allah di Perjanjian Baru. Marcion dipengaruhi oleh Cedro, seorang guru Gnostik yang percaya bahwa Tuhan di Perjanjian Lama berbeda dengan Tuhan dan Bapa Tuhan Yesus Kristus. ${ }^{1}$ Walaupun ajaran Marcion dianggap sesat namun pertanyaan tentang sikap Allah di Perjanjian Lama tetap menjadi pertanyaan hingga saat ini.

\section{PEMBATASAN MASALAH}

Artikel ini hanya akan membahas tiga masalah utama yang biasanya muncul ketika membahas perbedaan sikap Allah di Perjanjian Lama dan Perjanjian Baru yaitu kematian Uza (2 Samuel 6:6-7), Perang Suci di mana Tuhan menyuruh bangsa Israel untuk membunuh seluruh penduduk Kanaan termasuk anak-anak kecil, dan penghukuman Tuhan atas bangsa Israel selama padang gurun.

\section{KEMATIAN UZA (2 SAMUEL 6:6-7)}

Uza dibunuh oleh Tuhan ketika berusaha menjaga agar tabut Allah tidak jatuh ke tanah. Bukankah seharusnya Tuhan mengerti maksud baik Uza dan tidak membiarkannya ia dihukum mati? Untuk kasus ini adalah dua kesalahan yang terjadi, yaitu kesalahan Daud dan kesalahan Uza.

${ }^{1}$ Chris Price, Marcion, the Canon, the Law, and the Historical Jesus, A survey of Marcion's life and legacy, http://www.christianorigins.com/marcion.html (diakses 13 Juli 2015). 


\section{Kesalahan Daud}

Walter C. Kaiser, Jr. mengemukakan argument of silent yaitu Daud tidak memintapetunjuk dari Tuhan. ${ }^{2}$ Ketika sebelumnya Daud diserang oleh orang Filistin (2 Samuel 5:19, 23), ia meminta petunjuk dari Tuhan tetapi pada waktu ia ingin memindahkan tabut perjanjian, tidak dicatat di dalam tiga ayat pertama 2 Samuel bahwa Daud meminta petunjuk dari Tuhan padahal di 1 Tawarikh 13:1-3 (ayat-ayat paralelnya) Daud berunding dengan "pemimpin-pemimpin pasukan seribu dan pasukan seratus dan dengan semua pemuka."

Daud menggunakan cara bangsa Filistin untuk memindahkan tabut perjanjian dan bukan berdasarkan instruksi Tuhan. Ketika Tuhan menghukum bangsa Filistin karena merebut tabut perjanjian, bangsa Filistin mengembalikan tabut tersebut dengan meletakkannya ke atas sebuah kereta yang ditarik oleh dua ekor lembu (1 Samuel 6:7-11). Daud tidak mengindahkan perintah Tuhan di Bilangan 4:5-6 yang memerintahkan bahwa ketika tabut perjanjian akan dipindahkan maka harus ditutup dengan tabir penudung dan diusung di atas bahu orang Lewi. Jadi jelas di sini Daud berdosa karena tidak mengikuti hukum Tuhan dan menggantikannya dengan cara bangsa kafir.

\section{Kesalahan Uza}

Siapakah Uza? Uza adalah anak Abinadab. Ketika tabut perjanjian kembali ke Israel, yaitu di Bet-Semes, Tuhan "membunuh beberapa orang Bet-Semes karena mereka melihat ke dalam tabut TUHAN" dan juga "tujuh puluh orang dari rakyat itu" (1 Samuel 6:19), kemudian mereka mengirim tabut perjanjian ke Kiryat-Yearim dan ditaruh di rumah Abinadab. Tabut perjanjian berdiam di rumah ini paling sedikit selama 20 tahun (1 Samuel 7:2) dan Uza tumbuh menyaksikan bagaimana tabut perjanjian ini harus diperlakukan dan mengetahui penyebab tabut ini berada di rumahnya.

\footnotetext{
${ }^{2}$ Walter C. Kaiser, Jr., Ucapan Yang Sulit Dalam Perjanjian Lama (Malang: Departemen Literatur Seminari Alkitab Asia Tenggara, 1998), h.128.
} 
Uza seharusnya tahu bahwa ia tidak boleh menyentuh tabut perjanjian karena peristiwa di Bet-Semes dan larangan menyentuh barang-barang kudus agar tidak mati (Bilangan 4:15). Uza dibunuh oleh Tuhan "karena keteledorannya" (2 Samuel 6:7). Kata yang digunakan adalah שِ yang berarti dosa, kesalahan, tindakan yang tidak bijaksana atau sensitif, atau tindakan yang tidak sopan. James Swanson dalam Dictionary of Biblical Languages with Semantic Domains "merefer" tindakan ini sebagai tindakan yang tidak sopan/hormat walaupun di teks tersebut tidak tersirat motivasi jahat. ${ }^{3}$

Peristiwa ini memang tragis namun menunjukkan bahwa Tuhan sangat menjaga kekudusannya dan umat Allah harus mengikuti Firman Allah dan bukan pikiran mereka sendiri. Ketika bangsa Filistin tidak mendapat Firman Tuhan, Tuhan toleran dengan tindakan mereka menyentuh tabut perjanjian dan menggunakan kereta baru untuk mengangkutnya (1 Samuel 6) namun toleransi tidak berlaku bagi umat yang mendapat Firman. Melalui peristiwa ini tidak dapat disimpulkan bahwa Tuhan tidak sabar karena Tuhan menunjukkan kesabaran-Nya kepada bangsa Filistin.

Apakah peristiwa-peristiwa Tuhan membunuh manusia di Perjanjian Lama karena tidak menaruh hormat pada tabut perjanjian (yang merupakan representasi Tuhan) maka sikap Tuhan berbeda di Perjanjian Baru? Di Perjanjian Baru pun dapat ditemukan kisah Tuhan juga membunuh manusia karena tidak menaruh hormat kepada-Nya, misalnya Herodes ditampar oleh malaikat Tuhan "karena ia tidak memberi hormat kepada Allah" (Kisah Para Rasul 12:23) dan Ananias dan Safira dibunuh karena mendustai Allah (Kisah Para Rasul 5:1-11).

\section{PERANG SUCI}

Persoalan kedua yang diangkat untuk menunjukkan bahwa Allah di Perjanjian Lama adalah Allah yang kejam adalah peristiwa penghancuran

\footnotetext{
${ }^{3}$ James Swanson, Dictionary of Biblical Languages with Semantic Domains : Hebrew (Old Testament) (Oak Harbor: Logos Research Systems, Inc., 1997).
} 
kota Yerikho di mana Tuhan memerintahkan untuk menumpas bangsa Kanaan "sama sekali" (Ulangan 7:2) dan Yosua melakukan hal tersebut yaitu menumpas "segala sesuatu yang di dalam kota itu, baik laki-laki maupun perempuan, baik tua maupun muda, sampai kepada lembu, domba, dan keledai (Yosua 6:21).

Problem timbul karena seseorang menggunakan pola berpikir abad kedua puluh satu untuk melihat situasi pada zaman Yosua. Pada zaman sekarang tindakan genosida adalah tindakan yang dianggap tidak berperikemanusiaan namun hal ini adalah hal yang wajar pada zaman Yosua. Tindakan pemusnahan masal ini harus dipahami dengan latar belakang historis zaman Yosua. ${ }^{4}$ Tradisi mempersembahkan manusia dan harta benda serta tawanan adalah tradisi bangsa-bangsa di Timur Tengah kuno dan kebiasaan ini menolong seseorang untuk mengerti mengapa Yosua dan bangsa Israel tidak menganggap pembantaian penduduk Yerikho sebagai suatu kesalahan. ${ }^{5}$ Hal yang sama juga menyebabkan seseorang dapat mengerti mengapa Abraham tidak menganggap Allah jahat karena ingin Ishak dikorbankan.

Kadang ada yang berpikir bahwa Allah di Perjanjian Lama adalah Allah yang tidak sabar yang suka dengan segera menghukum manusia ketika mereka berdosa namun di kisah ini malah yang terjadi sebaliknya. Tuhan sudah berencana menghukum bangsa Kanaan sejak 400 tahun sebelumnya. Di dalam Kejadian 15:13-16 Tuhan berkata kepada Abraham bahwa nanti keturunannya akan menjadi bangsa yang besar dan diperbudak oleh bangsa Mesir dan nanti pada keturunan keempat mereka akan kembali ke Tanah Kanaan yang diduduki oleh orang Amori. Khusus dalam ayat ke-16 ada frasa "sebab sebelum itu kedurjanaan orang Amori itu belum genap" berarti Tuhan sedang menunggu dosa-dosa orang Amori (orang Kanaan) mencapai puncaknya baru Tuhan menghukum

\footnotetext{
${ }^{4}$ Ralph F. Wilson, "Why the Slaughter of Jericho? Devoted to Destruction - Herem" di bagian "4. Standards of the Time" jesuswalk.com. http://www.jesuswalk.com/joshua/herem.htm (diakses 30 Juli 2015).

${ }^{5}$ W.S. LaSor, D.A. Hubbard, dan F.W. Bush, Pengantar Perjanjian Lama 1: Taurat dan Sejarah (Jakarta: BPK Gunung Mulia, 2004),h. 291.
} 
bangsa tersebut. ${ }^{6}$ Penemuan naskah Ugarit di Ras Syamra, Siria, memberikan data bahwa penduduk Kanaan melakukan penyembahan berhala, sodomi, hubungan seks dengan hewan, sihir, dan pengorbanan anak. Hal ini mengakibatkan setiap generasi selanjutnya terpolusi dengan penyembahan berhala, tindakan seksual abnormal, dan darah. ${ }^{7}$ Kesabaran Tuhan menyebabkan Ia menunggu sampai kejahatan mencapai puncak, baru penghukuman dijatuhkan.

Gleason L. Archer memberikan argumen tentang perlunya pembinasaan massal. Ia mengatakan bahwa bahwa "ada saat-saat di mana pembedahan yang tuntas akan menyelamatkan nyawa orang yang terserang kanker." Ia beragumen karena "kanker kebobrokan moral" pada zaman Nuh akan menulari keluarga Nuh jika mereka tetap hidup, karena itu pemusnahan kota-kota di Kanaan (Yerikho, Ai, Makeda, Lakhis, Eglon, Debir, Negeb, Syefelah, dan Hazor) adalah perlu agar bangsa Israel dapat menegakkan agama monoteistik dan hidup sesuai dengan hukum Taurat. ${ }^{8}$ Hal yang sama juga dikemukakan oleh LaSor, Hubbard, dan Bush. Mereka memberikan ilustrasi bahwa dokter bedah tidak ragu untuk memotong bagian tubuh tertentu demi menyelamatkan hidup pasien maka bangsa Kanaan perlu ditumpas karena mengancam etika beragama dan kehidupan spritual bangsa Israel. Tuhan mengijinkan pembedahan dilakukan untuk kepentingan bangsa Israel. ${ }^{9}$ Pembenaran atas tindakan pemusnahan masal ini dapat dilihat ketika bangsa Israel tidak melakukan menumpas bangsa Kanaan, bangsa Kanaan "menyebabkan kemerosotan moral serta agama dari dua belas suku pada zaman Hakim-hakim (Hak. 2:1-3, 10-15, 19-23)". ${ }^{10}$

${ }^{6}$ Gleason L. Archer, Ensiklopedi Tentang Hal-hal Yang Sulit Dalam Alkitab (Malang: Gandum Mas, 2004), h. 264.

${ }^{7}$ Steve Fazekas, "Slaughter at Jericho: Could the loving God of the New Testament order the complete destruction of the inhabitants of Jericho found in the Old Testament?" answersingenesis.org, October 27, 2008. https://answersingenesis.org/contradictions-inthe-bible/slaughter-at-jericho (diakses 30 Juli 2015).

${ }^{8}$ Gleason L. Archer, Ensiklopedi Tentang Hal-hal Yang Sulit Dalam Alkitab, h. 264-265.

${ }^{9}$ W.S. LaSor, D.A. Hubbard, dan F.W. Bush, Pengantar Perjanjian Lama 1: Taurat dan Sejarah, h.292.

${ }^{10}$ Ibid., h.265. 
Di balik peristiwa yang sering disebut orang sebagai peristiwa yang mengenaskan karena Tuhan menghukum suatu bangsa sampai tuntas ternyata masih terdapat anugerah di balik peristiwa ini. Rahab dan keluarganya, karena takut akan Tuhan, terlepas dari peristiwa maut seperti Lot dan keluarganya dari penghancuran kota Sodom. Namun ada perbedaan yang cukup signifikan antara Lot dan Rahab karena Rahab adalah seorang perempuan berdosa, seorang pelacur dari bangsa kafir. Ketika Rahab menyembunyikan mata-mata Israel maka Rahab "telah menolak menjadi orang Kanaan" dan "mentransfer loyalitasnya kepada Israel". ${ }^{11}$ Hal ini berarti masih ada pengampunan bagi bangsa Kanaan yang mau bertobat dan takut akan Tuhan (Yosua 2:9-11) walaupun mereka adalah orang berdosa seperti Rahab, si pelacur.

\section{PENGHUKUMAN TUHAN ATAS BANGSA ISRAEL DI PADANG GURUN}

Persoalan ketiga yang membuat Allah di Perjanjian Lama seakanakan terlihat Allah yang kejam adalah Allah yang menghukum bangsa Israel selama di padang gurun. Sekilas terlihat bahwa Allah sering membunuh bangsa Israel secara masal dan kejam yaitu dengan api, tulah, ular tedung, tanah terbelah, dan lain-lain.

Ronald F. Youngblood menyebutkan ada lima krisis yang terjadi dari laut Merah sampai ke Gunung Sinai. ${ }^{12}$ Willem Hendrik Gispen menyebutkan ada empat sungut-sungut yang dilakukan oleh bangsa Israel di kitab Keluaran. ${ }^{13}$ Terence E. Fretheim menyebutkan ada sungut-sungut di kitab Keluaran dan hukuman Tuhan di kitab Bilangan. ${ }^{14}$ Dari ketiga pandangan tersebut dapat disusun sebuah tabel sebagai berikut:

\footnotetext{
${ }^{11}$ Richard S. Hess, Tyndale Old Testament Commentaries: Joshua (Illinois: Inter Varsity Press, 1996), p.134.

${ }^{12}$ Ronald F. Youngblood, Everyman's Bible Commentary: Exodus (Chicago: Moody Press, 1992), p.80-89.

${ }^{13}$ Willem Hendrik Gispen, Bible Student's Commentar: Exodus (Grand Rapids, Michigan: Regency Reference Libaray, 1992), pp.143, 154, 156, 165.

${ }^{14}$ Terence E. Fretheim, Interpretation, A Bible Commentary for Teaching and Preaching: Exodus (Louisville: John Knox Press, 1991), p. 174.
} 


\begin{tabular}{|c|c|c|c|}
\hline No & Peristiwa & Ayat & Hukuman Tuhan \\
\hline 1 & $\begin{array}{l}\text { Di pinggir Laut } \\
\text { Teberau, sebelum } \\
\text { menyeberang }\end{array}$ & $\begin{array}{l}\text { Kel. } \\
14: 10-12\end{array}$ & $\begin{array}{l}\text { Tidak ada hukuman dari } \\
\text { Tuhan. } \\
\text { Tuhan menyelamatkan } \\
\text { orang Israel dari tangan } \\
\text { orang Mesir (Kel. 14:30) }\end{array}$ \\
\hline 2 & Air pahit di Mara & $\begin{array}{l}\text { Kel. } \\
15: 24-25\end{array}$ & $\begin{array}{l}\text { Tidak ada hukuman dari } \\
\text { Tuhan. } \\
\text { Tuhan membuat air } \\
\text { menjadi manis. }\end{array}$ \\
\hline 3 & $\begin{array}{l}\text { Pemberian Manna di } \\
\text { padang gurun Sin }\end{array}$ & $\begin{array}{l}\text { Kel. 16:2- } \\
31\end{array}$ & $\begin{array}{l}\text { Tidak ada hukuman dari } \\
\text { Tuhan. } \\
\text { Tuhan memberi manna } \\
\text { pada waktu pagi dan } \\
\text { daging pada waktu senja. }\end{array}$ \\
\hline 4 & $\begin{array}{l}\text { Peristiwa di Masa dan } \\
\text { Meriba, orang Israel } \\
\text { haus }\end{array}$ & $\begin{array}{l}\text { Kel. 17:2- } \\
7\end{array}$ & $\begin{array}{l}\text { Tidak ada hukuman dari } \\
\text { Tuhan. } \\
\text { Tuhan memberi air. }\end{array}$ \\
\hline 5 & $\begin{array}{l}\text { Penyembahan Anak } \\
\text { Lembu Emas }\end{array}$ & $\begin{array}{l}\text { Kel. 32:1- } \\
35\end{array}$ & $\begin{array}{l}\text { Musa memerintahkan suku } \\
\text { Lewi untuk membunuh tiga } \\
\text { ribu orang Israel (Kel. } \\
\text { 32:28) dan Tuhan menulahi } \\
\text { bangsa Israel (Kel. 32:35). } \\
\text { Tuhan mau memusnahkan } \\
\text { semua tetapi tidak jadi. }\end{array}$ \\
\hline 6 & $\begin{array}{l}\text { Sungut-sungut di } \\
\text { Tabera }\end{array}$ & Bil. 11:1-3 & $\begin{array}{l}\text { Tuhan mengirim api (ayat } \\
\text { 1). }\end{array}$ \\
\hline 7 & $\begin{array}{l}\text { Bosan dengan Manna } \\
\text { di Kibrot-Taawa }\end{array}$ & $\begin{array}{l}\text { Bil. 11:4- } \\
\text { 23; 31-35 }\end{array}$ & $\begin{array}{l}\text { Tuhan mengirim burung- } \\
\text { burung puyuh dan Tuhan } \\
\text { murka serta memberikan } \\
\text { tulah (ayat } 33 \text { ). }\end{array}$ \\
\hline 8 & $\begin{array}{l}\text { Pemberontakan orang } \\
\text { Israel karena } \\
\text { mendengar } 10 \\
\text { pengintai }\end{array}$ & $\begin{array}{l}\text { Bil. 14:2- } \\
36\end{array}$ & $\begin{array}{l}\text { Orang Israel yang telah } \\
\text { melihat kemuliaan Tuhan } \\
\text { dan tanda-tanda mujizat di } \\
\text { Mesir dan di padang gurun } \\
\text { dan telah sepuluh kali } \\
\text { mencobai Tuhan dihukum } \\
\text { tidak akan masuk tanah } \\
\text { perjanjian (ayat 22-23). } \\
\text { Semua yang telah berumur } \\
20 \text { tahun ke atas akan mati }\end{array}$ \\
\hline
\end{tabular}




\begin{tabular}{|c|c|c|c|}
\hline No & Peristiwa & Ayat & Hukuman Tuhan \\
\hline & & & $\begin{array}{l}\text { di padang gurun (ayat 29) } \\
\text { kecuali Yosua dan Kaleb. } \\
\text { Bangsa Israel akan } \\
\text { menggembara selama } 40 \\
\text { tahun di padang gurun } \\
\text { sampai mereka mati semua } \\
\text { (ayat 33-34). }\end{array}$ \\
\hline 9 & Pemberontakan Korah & $\begin{array}{l}\text { Bil. 16:1- } \\
50\end{array}$ & $\begin{array}{l}\text { Tanah terbelah menelan } \\
\text { Korah, Datan, dan Abiram } \\
\text { (ayat } 31-33 \text { ). } \\
\text { Api dari Tuhan memakan } \\
\text { habis } 250 \text { orang (ayat } 35 \text { ). } \\
\text { Tulah dari tuhan } \\
\text { membunuh } 14.700 \text { orang } \\
\text { (ayat } 49 \text { ). }\end{array}$ \\
\hline 10 & $\begin{array}{l}\text { Pertengkaran bangsa } \\
\text { Israel dengan Musa }\end{array}$ & $\begin{array}{l}\text { Bil. 20:2- } \\
13\end{array}$ & $\begin{array}{l}\text { Tuhan menghukum Musa } \\
\text { tidak boleh masuk ke tanah } \\
\text { Kanaan }\end{array}$ \\
\hline 11 & Ular Tembaga & Bil 21:4-9 & $\begin{array}{l}\text { Tuhan mengirim ular-ular } \\
\text { tedung untuk membunuh } \\
\text { orang Israel, setelah itu } \\
\text { Tuhan menyuruh membuat } \\
\text { ular tembaga agar orang } \\
\text { Israel selamat. }\end{array}$ \\
\hline
\end{tabular}

Berdasarkan tabel di atas terlihat bahwa Tuhan tidak menghukum bangsa Israel sampai bangsa Israel menyembah patung Anak Lembu Emas. Setelah peristiwa ini baru Tuhan menghukum bangsa Israel bertubi-tubi.

Alasan Tuhan membawa bangsa Israel keluar dari Mesir adalah karena Tuhan telah berjanji kepada Abraham bahwa keturunannya akan kembali ke tanah perjanjian dan karena bangsa Israel mengeluh atas perbudakan yang mereka alami dan berseru minta tolong kepada Allah (Keluaran 2:23-24). Kemudian Tuhan membawa bangsa Israel keluar dengan tanda-tanda mujizat yang luar biasa yaitu 10 tulah yang menyatakan bahwa Tuhan lebih berkuasa daripada dewa-dewa sembahan orang Mesir. 
Namun apa yang dikatakan oleh bangsa yang telah dipimpin keluar oleh Tuhan:

1. Keluaran 14:11 "Apakah karena tidak ada kuburan di Mesir, maka engkau membawa kami untuk mati di padang gurun ini? Apakah yang kau perbuat ini terhadap kami dengan membawa kami keluar dari Mesir? Bukankah ini telah kami katakan kepadamu di Mesir: Janganlah mengganggu kami dan biarlah kami bekerja pada orang Mesir. Sebab lebih baik bagi kami untuk bekerja pada orang Mesir daripada mati di padang gurun ini”. Setelah keluhan ini, Tuhan tidak memberi hukuman tetapi menunjukkan mujizat yang luar biasa yaitu Tuhan membelah laut Teberau agar bangsa Israel terlepas dari kejaran Firaun.

2. Setelah menyeberang, ketika bangsa Israel kehausan, mereka bersungut-sungut : “Apakah yang akan kami minum?” (Keluaran 15:24). Tuhan tidak menghukum tetapi mengubah air menjadi manis di Mara.

3. Di padang gurun Sin bangsa Israel bersungut-sungut: “Ah, kalau kami mati tadinya di tanah Mesir oleh tangan TUHAN ketika kami duduk menghadapi kuali berisi daging dan makan roti sampai kenyang! Sebab kamu membawa kami keluar ke padang gurun ini untuk membunuh seluruh jemaah ini dengan kelaparan." (Keluaran 16:3). Tuhan tidak menghukum tetapi memberi makan mereka dengan manna dan daging.

4. Ketika bangsa Israel kehausan di Masa dan Meriba, mereka bersungut-sungut: "Mengapa pula engkau memimpin kami keluar dari Mesir, untuk membunuh kami, anak-anak kami dan ternak kami dengan kehausan" (Keluaran 17:3). Bangsa Israel mencoba Tuhan dengan mengatakan, "Adakah TUHAN di tengah-tengah kita atau tidak?" Tuhan tidak menghukum bangsa Israel tetapi memberi mereka minum.

Dari sungut-sungutnya, bangsa Israel adalah bangsa yang kurang ajar, setelah ditolong dari kesesakan perbudakan di Mesir kemudian menuduh Tuhan mau membunuh mereka dengan kehausan dan kelaparan serta mempertanyakan penyertaaan Tuhan. Walau mereka melihat mujizat-mujizat yang begitu spektakuler termasuk mujizat membelah air 
laut Teberau, ketika kehausan, mereka berpikir Tuhan melupakan mereka padahal mujizat mengeringkan Laut Teberau membuat bangsa Kanaan takut kepada Tuhan dan mengakui bahwa TUHAN adalah Allah di langit dan di bumi di bawah (Yosua 2:10-11). Walau Tuhan dinista demikian rupa, Tuhan masih bersabar dan tidak menghukum mereka.

Baru setelah peristiwa kelima, yaitu ketika bangsa Israel menyembah anak lembu emas, Tuhan menunjukkan murka-Nya dan bermaksud untuk memusnahkan seluruh Israel, namun hal itu dapat dicegah oleh Musa dan hati Tuhan melunak.

Setelah peristiwa ini bangsa Israel tetap bersungut-sungut kepada Tuhan:

1. Bilangan 11:1, Bangsa Israel bersungut-sungut tentang nasib buruk mereka.

2. Bilangan 11:4-6, "Siapakah yang akan memberi kita makan daging? Kita teringat kepada ikan yang kita makan di Mesir dengan tidak bayar apa-apa, kepada mentimun dan semangka, bawang prei, bawang merah dan bawang putih. Tetapi sekarang kita kurus kering, tidak ada sesuatu apa pun, kecuali manna ini saja yang kita lihat."

3. Bilangan 14:2-3, "Ah, sekiranya kami mati di tanah Mesir, atau di padang gurun ini! Mengapakah TUHAN membawa kami ke negeri ini, supaya kami tewas oleh pedang, dan isteri serta anak-anak kami menjadi tawanan? Bukankah lebih baik kami pulang ke Mesir?"

4. Bilangan 16:13-14, "Belum cukupkah, bahwa kamu memimpin kami keluar dari suatu negeri yang berlimpah-limpah susu dan madunya untuk membiarkan kami mati di padang gurun, sehingga masih juga engkau menjadikan dirimu tuan atas kami? Sungguh, engkau tidak membawa kami ke negeri yang berlimpah-limpah susu dan madunya, ataupun memberikan kepada kami ladang-ladang dan kebun-kebun anggur sebagai milik pusaka. Masakan engkau dapat mengelabui mata orang-orang ini?"

5. Bilangan 20:3-5, "Sekiranya kami mati binasa pada waktu saudarasaudara kami mati binasa di hadapan TUHAN! Mengapa kamu membawa jemaah TUHAN ke padang gurun ini, supaya kami dan 
ternak kami mati di situ? Mengapa kamu memimpin kami keluar dari Mesir, untuk membawa kami ke tempat celaka ini, yang bukan tempat menabur, tanpa pohon ara, anggur dan delima, bahkan air minum pun tidak ada?"

6. Bilangan 21:5, "Mengapa kamu memimpin kami keluar dari Mesir? Supaya kami mati di padang gurun ini? Sebab di sini tidak ada roti dan tidak ada air, dan akan makanan hambar ini kami telah muak."

Berulang kali Tuhan menyediakan air dan makanan namun bangsa Israel terus komplain dan tidak belajar dari providensia Tuhan sebelumnya. Siapakah dapat bertahan terhadap bangsa yang selalu berkeluh kesah ini? Musa yang tadinya merelakan agar hidupnya dicabut demi bangsa ini akhirnya menjadi tidak tahan dan mengatakan, "Dengarlah kepadaku, hai orang-orang durhaka, ..." (Bil. 20:10) dan memukul bukit batu dengan tongkat sebanyak dua kali sebagai reaksi kemarahannya padahal Tuhan hanya memerintahkan Musa untuk berkata kepada bukit batu tersebut. Apakah kita akan menyalahkan Tuhan kalau Tuhan menghukum semua orang yang berumur 20 tahun ke atas dan telah 10 kali mencobai Tuhan untuk tidak masuk ke tanah perjanjian dan mati di padang gurun? Kematian massal selama di padang gurun adalah pembersihan orang-orang durhaka agar keturunan mereka dapat masuk ke tanah perjanjian. Kematian orang tua mereka akan menyebabkan generasi selanjutnya tidak ingin kembali ke Mesir.

\section{SIMPULAN}

Dari ketiga kejadian yang paling memberi kesan bahwa Allah di Perjanjian Lama adalah Allah yang kejam dapat dilihat bahwa sebenarnya Allah sungguh panjang sabar. Kesan kejam muncul ketika seseorang tidak melihat konteks dengan lebih teliti atau tidak melihat rangkaian kejadian-kejadian yang menimbulkan kemarahan Tuhan. Ketika sesuatu rangkaian peristiwa yang panjang dilihat sebagai satu kejadian yang singkat maka kesan bahwa Allah kejam dapat terjadi namun jika melihatnya dari rangkaian peristiwa-peristiwa yang berkaitan maka orang akan menemukan bahwa Allah sungguh panjang sabar namun ketika 
manusia tidak hidup sesuai dengan aturan Tuhan maka bukan kesalahan Tuhan jika Ia menghukum manusia. Seringkali Tuhan menghukum dengan keras sebagai suatu peringatan dan janganlah melihat hal tersebut di luar konteks-konteks yang lain dimana Tuhan menunjukkan kesabaranNya atas dosa-dosa yang dilakukan manusia. Jika hanya mengambil sepenggal demi sepenggal teks tentang hukuman Tuhan yang tegas maka kesan negatif yang akan didapatkan tetapi marilah melihatnya dari konteks yang lebih luas. Dengan melihat rangkaian peristiwa maka kesan Allah kejam akan terlihat menjadi Allah yang tegas akan hukum-hukumNya.

\section{DAFTAR RUJUKAN}

Archer,Gleason L. Ensiklopedi Tentang Hal-hal Yang Sulit Dalam Alkitab. Malang: Gandum Mas, 2004.

Fretheim, Terence E. Interpretation, A Bible Commentary for Teaching and Preaching: Exodus. Louisville: John Knox Press.

Gispen, Willem Hendrik Bible Student's Commentar: Exodus. Grand Rapids, Michigan: Regency Reference Libaray.

Hess,Richard S. Tyndale Old Testament Commentaries: Joshua. Illinois: Inter Varsity Press, 1996.

Kaiser, Jr., Walter C. Ucapan Yang Sulit Dalam Perjanjian Lama. Malang: Departemen Literatur Seminari Alkitab Asia Tenggara, 1998.

LaSor, W.S,. D.A. Hubbard, dan F.W. Bush, Pengantar Perjanjian Lama 1: Taurat dan Sejarah. Jakarta: BPK Gunung Mulia, 2004.

Price, Chris. Marcion, the Canon, the Law, and the Historical Jesus, A survey of Marcion's life and legacy, http://www.christianorigins.com/marcion.html (diakses 13 Juli 2015).

Steve Fazekas, "Slaughter at Jericho: Could the loving God of the New Testament order the complete destruction of the inhabitants of 
92 Apakah Sikap Allah di Perjanjian Lama Berbeda Dengan di Perjanjian Baru?

Jericho found in the Old Testament?" answersingenesis.org, October 27, 2008. https://answersingenesis.org/contradictions-inthe-bible/slaughter-at-jericho (diakses 30 Juli 2015).

Swanson,James. Dictionary of Biblical Languages with Semantic Domains : Hebrew (Old Testament). Oak Harbor: Logos Research Systems, Inc., 1997.

Wilson,Ralph F. "Why the Slaughter of Jericho? Devoted to Destruction - Herem" di bagian "4. Standards of the Time" jesuswalk.com. http://www.jesuswalk.com/joshua/herem.htm (diakses 30 Juli 2015).

Youngblood, Ronald F. Everyman's Bible Commentary: Exodus. Chicago: Moody Press, 1992. 